\title{
Microvascular function, is there a link to myocardial viability: Is this another piece to the puzzle?
}

\author{
Fernanda Erthal, MD, ${ }^{\mathrm{a}}$ Natasha Aleksova, $M D,{ }^{\mathrm{a}}$ Aun Yeong Chong, $\mathrm{MD},{ }^{\mathrm{a}}$ \\ Robert A. de Kemp, PhD, a and Rob S. B. Beanlands, MD, FRCPC ${ }^{\mathrm{a}}$ \\ ${ }^{a}$ National Cardiac PET Centre and the CAPITAL Interventional investigator group, Division of \\ Cardiology, Department of Medicine, University of Ottawa Heart Institute, Ottawa, ON, Canada
}

Received Jun 3, 2016; accepted Jun 3, 2016

doi: 10.1007/s12350-016-0575-3

\section{See related article, pp. $1641-1650$}

\section{INTRODUCTION}

"It's always the small pieces that make the big picture',-Unknown author

The coronary microvasculature regulates flow resistance and perfusion pressure, and is capable of adapting to different conditions of metabolic demand. Our increasing ability to measure absolute myocardial flow both invasively and noninvasively, has led to greater understanding and some misunderstanding of the microvasculature and its role in the pathogenesis of myocardial disease states.

In this issue, Fukuoka et al. ${ }^{1}$ investigated microvascular function following revascularization for acute myocardial infarction (AMI). They studied 18 patients who were $14 \pm 5$ days post-AMI, and had undergone successful revascularization. Using ${ }^{13} \mathrm{~N}$-ammonia-FDG PET imaging, they observed an interesting phenomenon that myocardial flow reserve was reduced in flowmetabolism mismatch segments. Specifically, they note that "in successfully revascularized AMI, microvascular function is impaired despite preserved myocardial glucose metabolism in mismatch segments,' and that the

Fernanda Erthal and Natasha Aleksova are co-lead authors.

Reprint requests: Rob Beanlands, FRCPC, National Cardiac PET Centre and the CAPITAL Interventional investigator group, Division of Cardiology, Department of Medicine, University of Ottawa Heart Institute, 40 Ruskin Street, Ottawa, ON, K1Y 4W7, Canada; rbeanlands@ottawaheart.ca

J Nucl Cardiol 2017;24:1651-6.

1071-3581/\$34.00

Copyright (C) 2016 American Society of Nuclear Cardiology. recovery in these segments was incomplete. ${ }^{1}$ The authors speculate that the latter reflects microvascular dysfunction. This is a reasonable hypothesis, but there are several considerations when interpreting flow reserve measurements in the post-MI, post-revascularization patient.

Several important questions arise from these findings: 1. Is microvascular dysfunction the reason for impaired MFR measurements in this setting? 2. Is there any other evidence for microvascular dysfunction after revascularization post-MI? 3. What is the metabolic state of the myocardium after revascularization post-MI? 4. What is the clinical relevance of the observations?

\section{PET AND MICROVASCULAR DYSFUNCTION}

There are no direct methods for visualizing the microvasculature of the myocardium in-vivo. ${ }^{2}$ Currently, information about coronary microvascular function is obtained invasively with flow-wire measurements and/or noninvasively via PET imaging. ${ }^{2,3}$

PET measurements of myocardial blood flow (MBF) and myocardial flow reserve (MFR) assess the combined effects of microcirculatory dysfunction and epicardial stenosis. ${ }^{4}$ Although it is not currently possible to directly distinguish between them, MFR measurement adds prognostic information in the context of both ischemic and nonischemic cardiomyopathies. ${ }^{5-7}$ Microvascular dysfunction may be due to several mechanisms, including endothelial and smooth muscle dysfunction, microvascular spasm, sympathetic dysfunction, and altered microvascular remodeling ${ }^{8}$, and is recognized as one cause of impaired flow reserve. ${ }^{4}$ In the circumstance where the myocardium supplied by the infarct-related artery has been fully reperfused following PCI, as in the study by Fukuoka et al., any impairment in flow reserve may represent microvascular dysfunction 
(with a few caveats noted below), although it is not possible to determine which mechanism may be at play.

There are now several studies that demonstrate the value of MFR in populations of patients with suspected myocardial ischemia, showing that impaired MFR is associated with worse prognosis, and can be used to distinguish patients at high risk of having major adverse cardiovascular events (MACE) ${ }^{5-7}$ Also, the prognostic information of MBF is additive to standard perfusion imaging results, and can impact reclassification of risks. ${ }^{5-7}$ More recently, Majmudar et al. ${ }^{9}$ studied 510 patients with nonischemic and ischemic cardiomyopathy, and found that $\mathrm{MFR} \leq 1.65$ was related to increased risk of MACE regardless of the cardiomyopathy etiology. ${ }^{9}$ MFR impairment as a marker of microvascular dysfunction was also studied in hypertrophic and idiopathic dilated cardiomyopathies, and again was able to stratify patients at higher risk of having an unfavorable outcome. ${ }^{10,11}$

Even in the setting of normal coronaries, MFR may be impaired. Van den Heuvel et al. ${ }^{12}$ observed that MFR had an inverse correlation with left ventricular systolic wall stress $(r=-0.61, p=0.01)$ and a positive correlation between the extent of mismatch (decreased flow/ increased FDG uptake) and wall stress $(r=0.64$, $p=0.02$ ) in patients with idiopathic dilated cardiomyopathy. ${ }^{12}$ They also identified abnormal oxygen consumption in the mismatch areas, with a predominance of anaerobic over aerobic metabolism. ${ }^{12}$ The abnormal oxygen consumption in these mismatch areas may reflect hibernation or chronic ischemia in idiopathic dilated cardiomyopathies, and is a reminder of how complex and multifaceted the mismatch of flow and metabolism can be.

Fallavollita et al. ${ }^{13}$ showed that while there is reduced flow at rest, the hibernating myocardium reduces both function and oxygen metabolisms as part of an adaptive response to avoid supply-demand imbalance and at least partially protect against the development of ischemic injury. These downregulations of oxygen consumption, ${ }^{13}$ flow, and flow responsiveness suggest that flow-metabolism mismatch in the context of AMI may be more a "physiologic response" to the state of the myocardium than secondary to microvascular dysfunction per se. An alternate explanation for reduced MFR observed by Fukuoka et al. may be that this physiological down regulation persists for hibernating myocardium even after restoration of perfusion. It is also possible that the microvasculature itself is part of the downregulated response.

PET imaging and flow quantification post-AMI and in chronic remodeled myocardial infarction can be challenging. ${ }^{4}$ PET scans have limited spatial resolution, therefore, the ${ }^{13} \mathrm{~N}$-ammonia tracer concentration can be under- or overestimated in very thin myocardial walls due to the blurring effects of partial volume averaging and/or spillover contamination of activity from adjacent regions such as the blood pool, liver, and lungs. ${ }^{14}$

In the tracer kinetic model (Patlak) used by the authors, MBF estimation using ${ }^{13} \mathrm{~N}$-ammonia is based on the initial tracer uptake and retention rates. After ${ }^{13} \mathrm{~N}$ ammonia enters into the myocardium by passive diffusion and active transport, its retention is predominantly via the conversion of ${ }^{13} \mathrm{~N}$-ammonia and glutamic acid to ${ }^{13} \mathrm{~N}$-glutamine, which is mediated by glutamine synthetase and is an adenosine triphosphate-dependent process. Both transport and retention kinetics may be affected in the context of AMI, since reduced flow and ischemia can modify cell membrane permeability, energetics, and metabolism, changing the 'apparent' perfusion measured using ${ }^{13} \mathrm{~N}$-ammonia-PET. It has not been well studied whether such potential changes to ${ }^{13} \mathrm{~N}$-ammonia kinetics may bias MBF measurements during the 14 days post-MI, post-revascularized myocardium. Nonetheless, the effects of tracer kinetic changes must be considered when measuring flow using PET in injured myocardium.

\section{MICROVASCULAR OBSTRUCTION AND NO- REFLOW EFFECTS ON MYOCARDIAL FLOW RESERVE}

Following effective percutaneous coronary intervention (PCI), a considerable number of patients who present with ST-segment elevation myocardial infarction (STEMI) will have evidence of microvascular dysfunction or even microvascular obstruction (MVO) (ranges from $5 \%$ to $50 \%$ according to modality). ${ }^{15}$ "MVO" is multifactorial, including distal embolization, ischemia-reperfusion injury, capillary compression due to myocardial cell and interstitial edema, and obstruction formed by neutrophils and platelets. It is a very heterogeneous mixture of complete occlusion (no-reflow) and peripheral layers of less severe damage (lowflow) with dynamic evolving changes following the ischemic event. ${ }^{15}$

Cuculi et al. studied 82 patients with STEMI who underwent PCI and measured coronary flow reserve as well as the index of microcirculatory resistance $24 \mathrm{~h}$ and 6 months after the event. ${ }^{16}$ They observed that MVO detected by MRI was present in $47 \%$ of the patients and demonstrated that microvascular blood flow is not always restored immediately after revascularization with PCI, but does begin to recover within $24 \mathrm{~h}$ and continues to do so up to 6 months (especially in the group with MVO), showing the relationship between MVO and reduced flow. ${ }^{16}$ Patients with MVO also had significantly more fibrosis detected by late gadolinium 
Table 1. Patterns of flow-glucose metabolism and clinical relevance

\begin{tabular}{|c|c|c|c|}
\hline Perfusion & $\begin{array}{c}\text { Glucose } \\
\text { metabolism }\end{array}$ & Category & Clinical relevance \\
\hline Preserved & Preserved & Normal-viable & $\begin{array}{l}\text { Normal } \\
\text { Stunning } \\
\text { Ischemia (normal perfusion at rest and } \\
\text { abnormal during stress-may benefit from } \\
\text { revascularization) }\end{array}$ \\
\hline Reduced & Preserved & $\begin{array}{l}\text { Perfusion-metabolism } \\
\text { mismatch (hibernation } \\
\text { myocardium)-viable }\end{array}$ & $\begin{array}{l}\text { Likely to recover with adequate } \\
\text { revascularization; }{ }^{25} \text { may be observed } \\
\text { after post-MI revascularization }{ }^{1}\end{array}$ \\
\hline Reduced & Reduced & Scar (match)-nonviable & Unlikely to recover with adequate revascularization ${ }^{25}$ \\
\hline Preserved & Reduced & Reverse mismatch-viable & $\begin{array}{l}\text { LBBB with altered septal metabolism (may respond to } \\
\mathrm{CRT}),{ }^{40} \text { nonischemic cardiomyopathy, repetitive } \\
\text { stunning, may be observed after post-MI } \\
\text { revascularization }{ }^{31}\end{array}$ \\
\hline
\end{tabular}

enhancement sequence at 6 months. While the presence of more scars in those who develop microvascular dysfunction post-revascularization may be an important finding, no targeted therapies for microvascular dysfunction are currently available, and further research is required. $^{8,16}$ Thus, reduced flow with maintained metabolism associated with impaired flow reserve observed by Fukuoka et al., may reflect some level of MVO reducing perfusion but still viable metabolically active tissue, hence the perfusion-metabolism mismatch they observed.

Beygui et al. studied 41 patients with single vessel disease after AMI followed by successful primary PCI and described that coronary flow reserve (CFR) was correlated with the extent of the infarcted myocardiumat-risk but was not able to predict viability. ${ }^{17}$ Meanwhile, Montisci et al. also studied 24 patients after primary PCI following AMI and found an inverse correlation between CFR and no-reflow (similar to Cuculi et al.), but that both CFR and no-reflow were correlated with myocardial viability. ${ }^{18}$ Normal CFR $48 \mathrm{~h}$ after the event was a predictor of regional wall motion recovery. ${ }^{18}$ Correlation between CFR and wall motion recovery was also described by other groups, ${ }^{19,20}$ but the techniques and times of measurement after the acute event differ in the literature.

\section{FLOW-METABOLISM PATTERNS POST- INFARCTION IN PET}

Dysfunctional myocardium in patients with ischemic heart disease can be classified as either viable or nonviable. In the latter, the organized myocyte tissue is replaced by fibrosis, and no improvement with revascularization is expected. On the other hand, viable myocardium is characterized by a spectrum of mismatches between function, perfusion, and metabolism. ${ }^{21}$ Stunning is used to describe post-ischemic dysfunction that has delayed recovery, despite the return of resting perfusion to normal. The duration of the function impairment may vary, but myocardium typically will recover over time. ${ }^{22-24}$ In myocardial hibernation, on the other hand, the dysfunction is believed to be the result of downregulation after chronic or repeated ischemic events or repeated stunning. ${ }^{13,21}$ Hibernating myocardium may recover contractile function after adequate revascularization and time..$^{21,25,26}$

Perfusion-metabolism imaging can define states of myocardium as viable or nonviable prior to consideration of revascularization, and has been used to predict recovery of function and clinical outcomes with and without revascularization. $^{21,25,27-30}$

There are four flow-metabolism patterns described in perfusion/FDG PET myocardial viability studies: (i) preserved perfusion and glucose metabolism (viable but not ischemic at rest), (ii) reduced perfusion with preserved metabolism (viable mismatch $=$ hibernating myocardium), (iii) reduced perfusion and metabolism (nonviable match $=$ fibrotic scar), and (iv) preserved perfusion with reduced metabolism (reverse mismatch). (Table 1).

The first 3 patterns are well known and common. Less common is the reverse mismatch pattern, which may be seen in patients with left bundle branch block (LBBB) with altered septal metabolism in ischemic or nonischemic cardiomyopathy, in repetitive stunning or post-myocardial infarction. ${ }^{21,31,32}$ This pattern has been observed early post-revascularization following AMI. ${ }^{31}$ 
Anselm et al. described that the reverse mismatch pattern was seen in $48 \%$ of patients who underwent early PCI, with perfusion-FDG PET performed in the first 10 days following revascularization. ${ }^{31}$ They observed that reverse mismatch was more associated to regional wall motion abnormalities and was associated with shorter time to PCI. These authors hypothesized that there was "myocardial metabolic shift during the sub-acute phase of recovery," but further studies were needed. ${ }^{31}$ Fukuoka and colleagues represent such a study, but it is unclear why they did not report reverse mismatch. This may be because these segments were considered among those with normal perfusion. Taken together, these studies demonstrate that the post-MI myocardium undergoes complex metabolic changes that are less well understood than the typical perfusion-metabolism match and mismatch patterns observed in patients with ischemic heart disease and LV dysfunction before revascularization.

A wealth of literature has accumulated to support the application of perfusion-FDG PET viability imaging to guide decision making in patients with LV dysfunction being considered for revascularization. ${ }^{21,25,27,28,30,33,34}$ Although one recent trial called these observations into question, ${ }^{35}$ we and others have shown that in selected populations and experienced hands there appears to be good clinical value. ${ }^{27,34,36,37}$ Less is known regarding the role of perfusion-metabolism imaging to understand the pathophysiology of the post-infarct myocardium that has already been revascularized and whether this yields information that is of clinical or prognostic value. Furthermore, FDG uptake has been observed in association with inflammation including the post-MI myocardium, but with suboptimal relationships with radiolabelled white blood cells due to myocardial activity and different levels of microvascular function which may further impact inflammatory uptake. ${ }^{38,39}$ It is for this reason that many studies do not use FDG for viability detection in the first 2-4 weeks after large MIs. ${ }^{27}$

\section{CLINICAL RELEVANCE OF FINDINGS}

Fukuoka et al. described that nonviable segments had reduced rest MBF and MFR when compared to viable segments. Also, these mismatch segments (normal FDG uptake but low rest MBF) had reduced MFR and incomplete wall motion recovery, suggesting that the measurement of flow reserve after acute myocardial infarction may be a stronger tool than metabolic imaging to predict viability in this context. Despite these intriguing results, the study has some limitations and should be interpreted with caution. The post-MI myocardium is a complex state with vascular and myocardial changes that are in a state of flux, making it difficult to draw conclusions on the role of flow and FDG imaging in this context. Downregulation, MVO, inflammation as well as technical factors including altered tracer kinetics and partial volume effects may all contribute to this complexity. Furthermore, the clinical relevance of viability imaging after full revascularization is unclear, since there is currently no additional therapy to offer.

It is provocative to consider microvascular dysfunction as a mechanism for mismatch in post-MI dysfunction. Fukuoka et al. have shed some light on post-MI recovery, but further studies are needed. This study reminds us of the challenges of viability imaging post-MI. Given the complexity, it remains prudent to avoid FDG PET in the first 2-4 weeks following large transmural MI. Likewise, it remains prudent to exercise caution when interpreting flow and flow reserve studies in the infarct zone, until we have a better understanding of the evolving flow-metabolism patterns and their relationship in this setting. In the meantime, another piece has been placed into the puzzle.

\section{Acknowledgments}

RSB is a career investigator supported by the Heart and Stroke Foundation of Ontario, a Tier 1 Research Chair supported by the University of Ottawa, and the University of Ottawa Heart Institute Vered Chair in Cardiology. FE is Cardiac Imaging Fellow at the University of Ottawa Heart Institute supported by the UOHI Associates in Cardiology.

\section{Disclosures}

$R S B$ is or has been a consultant for and receives grant funding from GE Healthcare, Lantheus Medical Imaging, and Jubilant DraxImage. $R d K$ is a consultant for and receives grant funding and royalty revenues from Jubilant DraxImage.

\section{References}

1. Fukuoka Y., Nakano A., Tama N., et al. Impaired myocardial microcirculation in the flow-glucose metabolism mismatch regions in revascularized acute myocardial infarction. J Nucl Cardiol. 2016. doi:10.1007/s12350-016-0526-z.

2. Pries AR, Badimon L, Bugiardini R, et al. Coronary vascular regulation, remodelling, and collateralization: Mechanisms and clinical implications on behalf of the working group on coronary pathophysiology and microcirculation. Eur Heart J. 2015;36:313446. doi:10.1093/eurheartj/ehv100.

3. Gould KL, Johnson NP, Bateman TM, et al. Anatomic versus physiologic assessment of coronary artery disease. Role of coronary flow reserve, fractional flow reserve, and positron emission tomography imaging in revascularization decision-making. J Am Coll Cardiol. 2013;62:1639-53. doi:10.1016/j.jacc.2013.07.076.

4. Juneau D, Erthal F, Ohira H, et al. Clinical PET myocardial perfusion imaging and flow quantification. Cardiol Clin. 2016;34:6985. doi:10.1016/j.ccl.2015.07.013. 
5. Ziadi MC, Dekemp RA, Williams KA, et al. Impaired myocardial flow reserve on rubidium-82 positron emission tomography imaging predicts adverse outcomes in patients assessed for myocardial ischemia. J Am Coll Cardiol. 2011;58:740-8. doi: 10.1016/j.jacc.2011.01.065.

6. Herzog BA, Husmann L, Valenta I, et al. Long-term prognostic value of $13 \mathrm{~N}$-ammonia myocardial perfusion positron emission tomography added value of coronary flow reserve. J Am Coll Cardiol. 2009;54:150-6. doi:10.1016/j.jacc.2009.02.069.

7. Murthy VL, Naya M, Foster CR, et al. Improved cardiac risk assessment with noninvasive measures of coronary flow reserve. Circulation. 2011;124:2215-24. doi:10.1161/CIRCULATIONAHA. 111.050427.

8. Pries AR, Reglin B. Coronary microcirculatory pathophysiology: Can we afford it to remain a black box? Eur Heart J. 2016;. doi: 10.1093/eurheartj/ehv760.

9. Majmudar MD, Murthy VL, Shah RV, et al. Quantification of coronary flow reserve in patients with ischaemic and non-ischaemic cardiomyopathy and its association with clinical outcomes. Eur Heart J Cardiovasc Imaging. 2015;16:900-9. doi: 10.1093/ehjci/jev012.

10. Cecchi F, Olivotto I, Gistri R, Lorenzoni R, Chiriatti G, Camici PG. Coronary microvascular dysfunction and prognosis in hypertrophic cardiomyopathy. N Engl J Med. 2003;349:1027-35. doi: 10.1056/NEJMoa025050.

11. Neglia D, Michelassi C, Trivieri MG, et al. Prognostic role of myocardial blood flow impairment in idiopathic left ventricular dysfunction. Circulation. 2002;105:186-93.

12. van den Heuvel AF, van Veldhuisen DJ, van der Wall EE, et al. Regional myocardial blood flow reserve impairment and metabolic changes suggesting myocardial ischemia in patients with idiopathic dilated cardiomyopathy. J Am Coll Cardiol. 2000;35:19-28.

13. Fallavollita JA, Malm BJ, Canty JM. Hibernating myocardium retains metabolic and contractile reserve despite regional reductions in flow, function, and oxygen consumption at rest. Circ Res. 2003;92:48-55.

14. Herrero P, Markham J, Myears DW, Weinheimer CJ, Bergmann SR. Measurement of myocardial blood flow with positron emission tomography: Correction for count spillover and partial volume effects. Math Comput Model. 1988;11:807-12. doi:10.1016/ 0895-7177(88)90605-X.

15. Masci PG, Bogaert J. Post myocardial infarction of the left ventricle: The course ahead seen by cardiac MRI. Cardiovasc Diagn Ther. 2012;2:113-27. doi:10.3978/j.issn.2223-3652.2012.04.06.

16. Cuculi F, De Maria GL, Meier P, et al. Impact of microvascular obstruction on the assessment of coronary flow reserve, index of microcirculatory resistance, and fractional flow reserve after STsegment elevation myocardial infarction. J Am Coll Cardiol. 2014;64:1894-904. doi:10.1016/j.jacc.2014.07.987.

17. Beygui F, Le Feuvre C, Helft G, Maunoury C, Metzger JP. Myocardial viability, coronary flow reserve, and in-hospital predictors of late recovery of contractility following successful primary stenting for acute myocardial infarction. Heart $\mathrm{Br}$ Card Soc. 2003;89:179-83.

18. Montisci R, Chen L, Ruscazio M, et al. Non-invasive coronary flow reserve is correlated with microvascular integrity and myocardial viability after primary angioplasty in acute myocardial infarction. Heart Br Card Soc. 2006;92:1113-8. doi:10.1136/hrt.2005.078246.

19. Suryapranata H, Zijlstra F, MacLeod DC, van den Brand M, de Feyter PJ, Serruys PW. Predictive value of reactive hyperemic response on reperfusion on recovery of regional myocardial function after coronary angioplasty in acute myocardial infarction. Circulation. 1994;89:1109-17.
20. Lepper W, Hoffmann R, Kamp O, et al. Assessment of myocardial reperfusion by intravenous myocardial contrast echocardiography and coronary flow reserve after primary percutaneous transluminal coronary angioplasty [correction of angiography] in patients with acute myocardial infarction. Circulation. 2000;101:2368-74.

21. Ghosh N, Rimoldi OE, Beanlands RSB, Camici PG. Assessment of myocardial ischaemia and viability: Role of positron emission tomography. Eur Heart J. 2010;31:2984-95. doi:10.1093/eurheartj/ ehq361.

22. Braunwald E, Kloner RA. The stunned myocardium: Prolonged, postischemic ventricular dysfunction. Circulation. 1982;66:11469. doi:10.1161/01.CIR.66.6.1146.

23. Ambrosio G, Betocchi S, Pace L, et al. Prolonged impairment of regional contractile function after resolution of exercise-induced angina evidence of myocardial stunning in patients with coronary artery disease. Circulation. 1996;94:2455-64. doi:10.1161/01. CIR.94.10.2455.

24. Barnes E, Hall RJC, Dutka DP, Camici PG. Absolute blood flow and oxygen consumption in stunned myocardium in patients with coronary artery disease. J Am Coll Cardiol. 2002;39:420-7.

25. Schinkel AFL, Bax JJ, Poldermans D, Elhendy A, Ferrari R, Rahimtoola SH. Hibernating myocardium: Diagnosis and patient outcomes. Curr Probl Cardiol. 2007;32:375-410. doi: 10.1016/j.cpcardiol.2007.04.001.

26. Tillisch J, Brunken R, Marshall R, et al. Reversibility of cardiac wallmotion abnormalities predicted by positron tomography. N Engl $\mathrm{J}$ Med. 1986;314:884-8. doi:10.1056/NEJM198604033141405.

27. Beanlands RSB, Nichol G, Huszti E, et al. F-18-fluorodeoxyglucose positron emission tomography imaging-assisted management of patients with severe left ventricular dysfunction and suspected coronary disease: A randomized, controlled trial (PARR-2). J Am Coll Cardiol. 2007;50:2002-12. doi:10.1016/j.jacc.2007.09.006.

28. D'Egidio G, Nichol G, Williams KA, et al. Increasing benefit from revascularization is associated with increasing amounts of myocardial hibernation: A substudy of the PARR-2 trial. JACC Cardiovasc Imaging. 2009;2:1060-8. doi:10.1016/j.jcmg.2009.02.017.

29. Di Carli MF, Davidson M, Little R, et al. Value of metabolic imaging with positron emission tomography for evaluating prognosis in patients with coronary artery disease and left ventricular dysfunction. Am J Cardiol. 1994;73:527-33.

30. Allman KC, Shaw LJ, Hachamovitch R, Udelson JE. Myocardial viability testing and impact of revascularization on prognosis in patients with coronary artery disease and left ventricular dysfunction: A meta-analysis. J Am Coll Cardiol. 2002;39:1151-8.

31. Anselm DD, Anselm AH, Renaud J, et al. Altered myocardial glucose utilization and the reverse mismatch pattern on rubidium82 perfusion/F-18-FDG PET during the sub-acute phase following reperfusion of acute anterior myocardial infarction. J Nucl Cardiol Off Publ Am Soc Nucl Cardiol. 2011;18:657-67. doi: 10.1007/s12350-011-9389-5.

32. Thompson K, Saab G, Birnie D, et al. Is septal glucose metabolism altered in patients with left bundle branch block and ischemic cardiomyopathy? J Nucl Med Off Publ Soc Nucl Med. 2006; 47:1763-8.

33. Di Carli MF, Asgarzadie F, Schelbert HR, et al. Quantitative relation between myocardial viability and improvement in heart failure symptoms after revascularization in patients with ischemic cardiomyopathy. Circulation. 1995;92:3436-44.

34. Abraham A, Nichol G, Williams KA, et al. 18F-FDG PET imaging of myocardial viability in an experienced center with access to 18F-FDG and integration with clinical management teams: The Ottawa-FIVE substudy of the PARR 2 trial. J Nucl Med Off Publ Soc Nucl Med. 2010;51:567-74. doi:10.2967/jnumed.109.065938. 
35. Bonow RO, Maurer G, Lee KL, et al. Myocardial viability and survival in ischemic left ventricular dysfunction. $\mathrm{N}$ Engl $\mathrm{J}$ Med. 2011;364(17):1617-25. doi:10.1056/NEJMoa1100358.

36. Mielniczuk LM, Beanlands RS. Does imaging-guided selection of patients with ischemic heart failure for high risk revascularization improve identification of those with the highest clinical benefit? Imaging-guided selection of patients with ischemic heart failure for high-risk revascularization improves identification of those with the highest clinical benefit. Circ Cardiovasc Imaging. 2012;5:262-70. doi:10.1161/CIRCIMAGING.111.964668 discussion 270.

37. McArdle B, Shukla T, Bernick J, et al. Long term follow-up of outcomes with F-18-fluorodeoxyglucose positron emission tomography imaging-assisted management of patients with severe left ventricular dysfunction secondary to coronary disease. Circulation. 2014;130:A13207.
38. Prato FS, Butler J, Sykes J, et al. Can the inflammatory response be evaluated using 18F-FDG within zones of microvascular obstruction after myocardial infarction? J Nucl Med Off Publ Soc Nucl Med. 2015;56:299-304. doi:10.2967/jnumed.114.147835.

39. Lautamäki R, Schuleri KH, Sasano T, et al. Integration of infarct size, tissue perfusion, and metabolism by hybrid cardiac positron emission tomography/computed tomography: Evaluation in a porcine model of myocardial infarction. Circ Cardiovasc Imaging. 2009;2:299-305. doi:10.1161/CIRCIMAGING.108.846253.

40. Birnie D, de Kemp RA, Tang AS, et al. Reduced septal glucose metabolism predicts response to cardiac resynchronization therapy. J Nucl Cardiol Off Publ Am Soc Nucl Cardiol. 2012;19(1):73-83. doi:10.1007/s12350-011-9483-8. 